\title{
Seeing is questioning: prompting sustainability discourses through an evocative visual agenda
}

\author{
Dana C. Thomsen $^{1}$
}

\begin{abstract}
I explore the potential utility of visual imagery to engage viewers in connecting ways with dynamic social-ecological contexts. Constructing photographs in response to the mass stranding of birds (shearwaters) on the east coast of Australia in 2013, I demonstrate the potential of wildlife and landscape photography to represent the impacts of environmental change at personal, relational, spatial, and temporal scales simultaneously. In so doing, I suggest that the production and interpretation of photographs can lead to responses that: (1) foster attentive forms of vision in familiar contexts; (2) provoke reflexive self-examination and critiques of broader, complex systems; (3) develop emotional connections with those impacted by social-ecological change; and (4) provide a foundation for precautionary behavioral change in uncertain contexts. Consequently, 'seeing' is reconceptualized as questioning, not believing, and as a valuable contribution to learning for sustainability and resilience.
\end{abstract}

Key Words: art; Australia; autoethnography; environmental change; interdisciplinary; learning for sustainability; photography; socialecological change; visual communication

\section{INTRODUCTION}

In a world of rapid social-ecological change, the need for effective communication is essential to the facilitation of sustainable relationships between people and the complex social-ecological systems that they inhabit and influence. This is especially so if it is assumed that the knowledge, attitudes, and behaviors underpinning sustainability are all mediated through communication (Godemann and Michelsen 2011). This assumption does not ignore or deny the complex interrelationships between knowledge, attitudes, and behaviors and the so-called "gap" between these (e.g., Kollmuss and Agyeman 2002). Nevertheless, it does acknowledge the valuable role of communication, and especially visual communication, in synthesizing complex information, portraying new ideas, prompting thought and dialogue, and rapidly conveying ideas (Nicholson-Cole 2005). Indeed, there has been recent and increased interest in the visual communication of environmental issues across several disciplines (Hansen and Machin 2013) providing a foundation for exploring how visual images may have particular relevance to communicating the intricacies associated with social-ecological systems.

To contribute to the theory and practice of communicating socialecological change visually, I explored the potential of photography of familiar landscapes to provoke responses and connect people with change in meaningful and transformative ways. Visual methods are well established in several disciplines, such as visual anthropology and visual sociology, with associated understandings informing more recent interdisciplinary endeavors (Pink 2003). Interdisciplinary insights from geography, ecology, environmental communication, visual studies, and visual anthropology are utilized to inform the development of photographs deliberately constructed to expand the "emotional environs" of viewers by linking experiences of place with broader, if uncertain, contexts (Davidson and Milligan 2004). In particular, visual geographical practices examining space, time, people, place, and the other (Schwartz 1996) are used in an attempt to construct photographs that represent impacts of socialecological change in everyday landscapes and to engage emotions as a "connective tissue" (Davidson and Milligan 2004). In so doing, I present an approach to represent social-ecological change visually at personal, relational, spatial, and temporal scales simultaneously with the potential to prompt increased engagement with sustainability discourses.

\section{Visualizing social-ecological change}

Images function as meaningful symbols and metaphors in environmental discourses (Seppänen and Väliverronen 2003). Maps, GIS visualizations, photography, info graphics, and other digital forms of display have all been used to visualize socialecological change. The majority of recent studies concerning the visualization of social-ecological change have examined previously published imagery from various sources including books, newspapers, websites, reports, film, and television (e.g. Seppänen and Väliverronen 2003, Doyle 2007, Howell 2011, O'Neill 2013). However, an emergent focus explores the production of imagery by researchers in various collaborations with research participants, including computer-generated visualizations, e.g., maps, 3D visualizations, and photorealistic visualizations (e.g., Dockerty et al. 2005), PhotoVoice (e.g., Baldwin and Chandler 2010), and participatory video (e.g., Mistry et al. 2014). Both approaches indicate that emotional responses to social-ecological change can be achieved through the use of imagery that viewers can relate to, such as animal symbols (Seppänen and Väliverronen 2003), or imagery that is of national, local, or iconic significance to target audiences (Nicholson-Cole 2005, Sheppard 2005, Shaw et al. 2009). Such imagery can be especially effective when causes and consequences are visible and already publicly accepted, such as the burning of rain forests (Seppänen and Väliverronen 2003).

However, Hansen and Machin (2013:156) caution that a reliance on generic, symbolic, and decontextualized images of environments in news and advertising media can result in a "visual disconnect from concrete processes" that tends to support individual responses to environmental issues rather than broader structural change. For example, analysis of climate change impacts imagery used in the media reveals predominant use of 
iconic visuals that are spatially, temporally, and personally removed from most viewers' immediate contexts, e.g., glacial landscapes, polar bears, drought (O'Neill 2013). In addition, some of the most recognized climate science images are abstract visualizations based on climate model simulations (e.g., global temperature graphs and world maps) that represent the "front end of an artificial and highly complex process" and function to further remove viewers from the nuances of change and the caveats of scientific representations (Schneider 2012:191). Consequently, one of the most widely recognized issues deemed responsible for limited engagement and meaningful adaptation in response to complex sustainability dilemmas, such as climate change, is that they are perceived to be spatially and temporally distant and are seldom linked to personal experiences or direct exposure (e.g., Lorenzoni et al. 2007, Moser 2010). Such disconnects indicate that use of familiar imagery with pre-existing narratives may be insufficient in generating responses to socialecological change in which change processes are contested (e.g., O'Neill 2013), uncertain (e.g., Ravetz 2006, Smith 2009, Moser 2010, O'Neill and Smith 2014), complex (e.g., Ravetz 2006, Smith 2009, Moser 2010, Thomsen et al. 2012), or invisible (e.g., Doyle 2007, Moser 2010).

In overcoming some of these issues, one approach is to depict the consequences of change over time, i.e., through compositions using multiple images representing past, present, and future contexts in sequence (O'Neill and Smith 2014), requiring viewers to "fill in the gaps" (Schneider 2012:187). Recent developments in the application of this strategy can be seen in the field of computer-generated imagery in which contemporary landscape imagery is contrasted with hypothetical visualizations of future contexts under a range of scenarios and timeframes (e.g., Dockerty et al. 2005, Sheppard 2005). Examples of this approach include GIS-based simulations and photo-realistic visualizations that attempt to make abstract notions of change and related phenomena more certain, tangible, and relevant to local and/or contemporary contexts; such as the depiction of sea level rise, decreases in snow cover and ice thickness, changes in forest and cropping species, and low carbon futures with wind and solar farms deployed across the landscape (Dockerty et al. 2005, Sheppard 2005, Shaw et al. 2009).

Visualizations are useful tools in imagining alternative futures and anticipating the consequences of particular decisions, activities, and processes, anthropogenic or otherwise. Findings from Marx et al. (2007:47) suggest that the "concretization of abstract risks" into "vicarious experience" can produce emotional responses and motivate action. However, several authors caution that such visualizations "should not be interpreted too literally" (Dockerty et al. 2005:315), stress the importance of transparency in production processes (Sheppard 2001, Dockerty et al. 2005), and highlight ethical concerns when deliberately attempting to persuade audiences by engaging emotions in landscape visualizations (Sheppard 2005). Similarly, studies of "real" or "experienced" change over time, such as photographic sequences illustrating glacial retreat, suggest that such imagery could result in feelings of regret and nostalgia (Doyle 2007), and recent reviews have questioned the impacts on self-efficacy when audiences experience negative emotional states in response to viewing deteriorating environmental conditions (O’Neill and Smith 2014) or if threats to place identity are perceived (Moser 2014).
Given the inherent uncertainties and ethical dilemmas present in constructing realistic images of future contexts and calls for imagination and interdisciplinary insights to generate new images beyond scientific representations (e.g., Schneider 2012), I explored the potential of wildlife and landscape photography to represent contemporary social-ecological change in compelling, contextualized, and engaging ways. As the following sections highlight, this offers an opportunity to exploit uncertainties in photography and social-ecological change in a way that initiates questioning, rather than defensive or dismissive responses. It also provides opportunities to connect people to local and global landscapes simultaneously through the development of more attentive ways of seeing in familiar contexts (Alpers 1991, Bissell 2009).

\section{Photography, representation, and evocation}

As with other visual imagery, photographs can be constructed to represent selected elements of social-ecological systems with diverse interpretations being technically, socially, and culturally mediated (Seppänen and Väliverronen 2003, Schneider 2012, Wolff 2012). Nevertheless, "of all forms of representation, images can most easily hide their social construction. They are consistently associated with realism, a sense that what is seen accurately reflects what existed at the time of production"(Peeples 2011:374-375).

Across several disciplines, issues of power and agency are discussed as a postmodern caution to the naïve consumption of photographs to avoid assumptions of "reality" or reifying a particular gaze (Mitchell 2002, Doel and Clarke 2007, Roberts 2012). As such, photographs can be conceived as "social constructs capable of performing ideological work" (Schwartz 1996:35) with power variously "given to" them (Wolff 2012:6) through a complex assemblage of production and interpretative processes at each developmental moment (Rose 2000).

Recent insights from visual anthropology suggest that such ambiguities can expand the communicative potential of photographs and allow for a shift in "understanding the photograph realistically as visually represented data to understanding the image as an expressive medium for evoking experience" (Mjaaland 2009:409). In this way, the inherent uncertainties in the production and interpretation of photographs facilitate new opportunities for communication and reinforce the potential for the invocation of sustainability discourses. In particular, Mjaaland (2009:394) highlights the potential for an "artistic orientation toward the expressive" and the "repositioning of the researcher" from "observing" to "social agent."

In deliberately seeking agency, the tensions of the "toxic sublime" (Diehl 2006, Peeples 2011) offer insights into a range of responses that may be invoked through various compositional choices employed by the researcher/photographer. As with other recent variants of the sublime (e.g., technological sublime and industrial sublime), a toxic sublime stems from increasing recognition of the potential of human-altered, as opposed to natural landscapes, and the altering agents and processes, to inspire horror and fascination simultaneously (Diehl 2006, Crang 2010, Peeples 2011). These notions of the sublime are distinguished from the conventional sublime through the implication of human agency in changing landscapes to produce a range of heightened 
emotional responses, whereby fear/awe of nature is replaced by fear/awe of our collective impacts and ourselves (Hitt 1999).

Of particular relevance to this article, Peeples (2011:387) reviewed Edward Burtynsky's contaminated landscape photography to identify tensions between beauty and ugliness, magnitude and insignificance, the known and the unknown, and security and risk as subjective elements of a toxic sublime capable of prompting "active contemplation of the self in relation to the object." Her analysis demonstrates the potential for photographic compositional choices to attract viewers and to "render images fraught with tensions that require thought and contemplation, which...provide the impetus necessary for attitudinal change" (Peeples 2011:380). In particular, Peeples noted that the toxic sublime can prompt questions of the "personal, social and environmental ethics that allows these places" (Peeples 2011:380), illustrating the potential for cultivating discourses related to broader and/or causative social-ecological contexts.

\section{METHODS}

\section{Developing an evocative visual agenda}

Inspired by the potential of photography to represent contemporary social-ecological change and opportunities to reposition in a more engaged research role, the following discussion presents an initial attempt at pursuing an evocative visual agenda through creative landscape and wildlife photography. Through deliberate content and compositional choices, I aimed to avoid the pitfalls of dystopian environmental and sustainability discourses to construct images of the impacts of social-ecological change with the potential to engage audiences with issues they might otherwise ignore or avoid.

Drawing on Rose's (2008:155) categorization of "photographs as evocation," the images were constructed to encourage contemplation and to avoid being either "taken-for-granted illustrations" or "problematic representations" with easily accessible or pre-existing narratives. Disruption (Rose 2008) is a central purpose for the work, and I sought the unfamiliar in familiar landscapes to surprise viewers, stimulate curiosity, and to encourage new ways of seeing in the landscape. Consequently, the creative process considered combining emotionally heightened spaces (Anderson and Smith 2001), visualizing everyday geographies (Bissell 2009), and relatable national and local imagery to generate emotional responses (e.g., NicholsonCole 2005, Sheppard 2005, Shaw et al. 2009). The tensions of the toxic sublime (Diehl 2006, Peeples 2011) were also utilized to create enticing content with the potential to cultivate incongruity and intrigue in response to the photographs.

The evocative visual agenda was constructed in response to successive mass strandings (wrecks) of birds (shearwaters) in Southeast Queensland and Northern New South Wales, Australia, in late 2013. Although wrecks of shearwaters during seasonal migration to breeding grounds in Australia and New Zealand are not uncommon on coastlines further south (e.g., March and Brewin 2013, Schriever 2013), in these locations, Southeast Queensland in particular, wrecks of this scale represent an unusual and unanticipated instance of environmental change in an everyday landscape familiar to residents and tourists alike. Hence, the potential for disrupting everyday vision and invoking emotional and questioning responses was anticipated by the novelty and scale of the wrecks and also the ambiguity and impact of the causative processes.

My autoethnographic approach explores the development of photographs for an evocative visual agenda toward: (1) fostering attentive forms of vision in familiar contexts; (2) provoking reflexive self-examination and critiques of broader, complex systems; (3) developing emotional connections with those impacted by social-ecological change; and (4) providing a foundation for precautionary behavioral change in uncertain contexts.

The photographs were taken on a digital, mirrorless camera during the wrecks in October-November 2013 and in the following months of December 2013-February 2014. Macro and zoom lens were used and postproduction was conducted using Adobe Lightroom with typical minor adjustments made to tone, clarity, and vibrance. Consistent with a deliberately evocative agenda, elements likely to reduce the visual impact of the deceased, e.g., rocks and disturbed sand, were removed through selective cropping or by applying the spot removal tool as part of a subjective compositional process designed to gain attention and encourage closer inspection and introspection. An autoethnographic journal was also maintained during this time.

\section{RESULTS AND DISCUSSION}

\section{Fostering attentive vision in familiar contexts}

Journal entry 12 December 2013:

I went to find the face of environmental change. I didn't have to walk far-just a few steps down the street to the shore I found the eyes-at least until they were picked out. Then I found the flies, the feathers, and the bones... every few paces.

All the figures employ the compositional technique of montage to capture spatial and temporal change across multiple scales to draw attention and sensitize viewers to environmental change in familiar, everyday places. In terms of content, these photographs represent the coastal landscapes of Southeast Queensland and Northern New South Wales, well-known and iconic landscapes of national interest that form part of the routine visual experience of many Australians. The photographs also focus on dead shearwaters lying on, or partly embedded within, the seashore. The photographs differ from contemporary exemplars in this genre, e.g., the large scale industrial sites of Edward Burtynsky, the emaciated birds full of plastic on the remote Midway Islands of the Northern Pacific by Chris Jordan, and the slew of climate change imagery depicting melting polar regions, in which the photographs catch viewers' attention by representing sites commonly inaccessible and unknown through direct experience. Importantly, this agenda is based on the assumption that these photographs also differ from the imagery and visual experiences commonly associated with the coastal landscape in the southeast of Queensland and the north of New South Wales of clean, sandy beaches, a popular aesthetic with residents and tourists alike. Although the occasional dead seabird may be expected, the attention-commanding scene posed in Figure 1 of multiple dead birds contrasts sharply with the everyday and iconic visualizations. 
Fig. 1. Montage of shearwaters, Southeast Queensland, Australia. 2013 October 20-2013 December 05. Source: Author's own photographs.
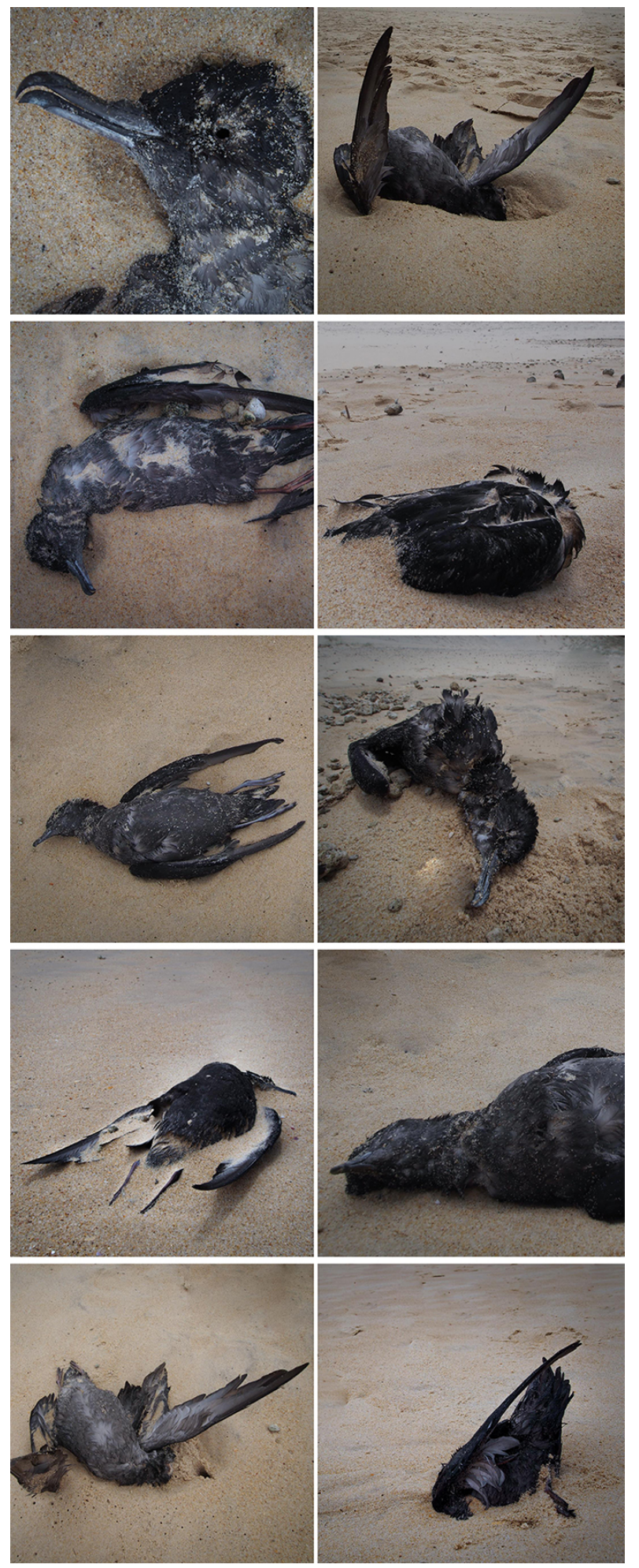

Building on the assumption that wrecks of seabirds are an uncommon sight in this landscape, the production processes of Figure 1 took place over several weeks. Although each wreck was traumatic to experience firsthand and involved hundreds of dead and dying birds washing onshore, capturing the enormity of the events in one or two photographs was problematic. The bodies were strewn along the shoreline at various intervals, and many bodies were periodically removed with each tide. In Figure 1, I have attempted to overcome this difficulty by combining macro scale imagery with montage to represent the landscape at intimate and extensive spatial scales simultaneously. Doel and Clarke (2007:890) referred to the process of montage as "the juxtaposition of symbolically charged images for critical affect." Cutting and repasting the landscape allowed me to represent the spatial and numerical extent of the wrecks in one concise image without losing the resolution of individual birds. The result is a novel composite image that invokes the horror of content and the horror of form (Doel and Clarke 2007) as viewers are invited into multiple personal, almost uncomfortably close, spaces of the deceased.

Using montage to represent many dead birds goes some way toward illustrating the scale of the issue across time and space and could be enhanced further through a larger image depicting more bodies. Nevertheless, choosing "a scale that matters to people" is important in linking responses and action (Shaw et al. 2009:461). Hence, Figure 1, which retains the resolution of each individual and depicts the unique qualities of each final resting position, while simultaneously indicating the extent of the event, is more likely to facilitate connections and generate emotional responses than an image that displays numerical extent alone. A successful exemplar of depicting singular and multiple scales simultaneously is provided by photographer Chris Jordan in his Running the Numbers: An American Self Portrait series of dynamic, interactive artworks that zoom in from the many individuals/subjects/objects involved until the resolution reveals a much more limited and personalized view (see http://www. chrisjordan.com).

However, in isolation, Figure 1 appears more likely to generate a dystopian than sublime response. Moreover, in studies of human victims, Joffe (2008) notes that emotional responses begin to diminish as soon as more than one individual is presented. In the following section, fewer birds are represented and this time montage is employed not to prompt awareness or indicate scale, but to invoke questions associated with ambiguous causal processes.

\section{Invoking uncertainty, provoking questions: re-examining self and} systems

Journal entry 22 December 2013

Today people using the beach began asking me why the birds had died as I took photos. I found myself wanting to answer with confidence and certainty. In a clumsy attempt, I began listing all the possibilities as I struggled, uncomfortably, with the uncertainty. I went home and 'Googled' for a more adequate answer, but only discovered even more questions.

The compositional choices in Figures 2 and 3 to invoke uncertainty and provoke questions, build on the assertion of 
Seppänen and Väliverronen (2003:60) that "although some environmental changes are visible to the naked eye, the causes, consequences and remedies always have to be deduced separately on a case-by-case basis." As noted earlier, the invisibility of causes has led to uncertainty being a major barrier to the accurate imaging, acceptance, and understanding of climate change. However, at the same time, exploiting uncertainty can also assist in the production of visual images that avoid the kind of superficial and overly familiar public discourses with environmental issues noted by Hansen (2010).

Fig. 2. Shearwater burial triptych, Southeast Queensland, Australia. 2013 October 20-2013 December 05. Source: Author's own photographs.
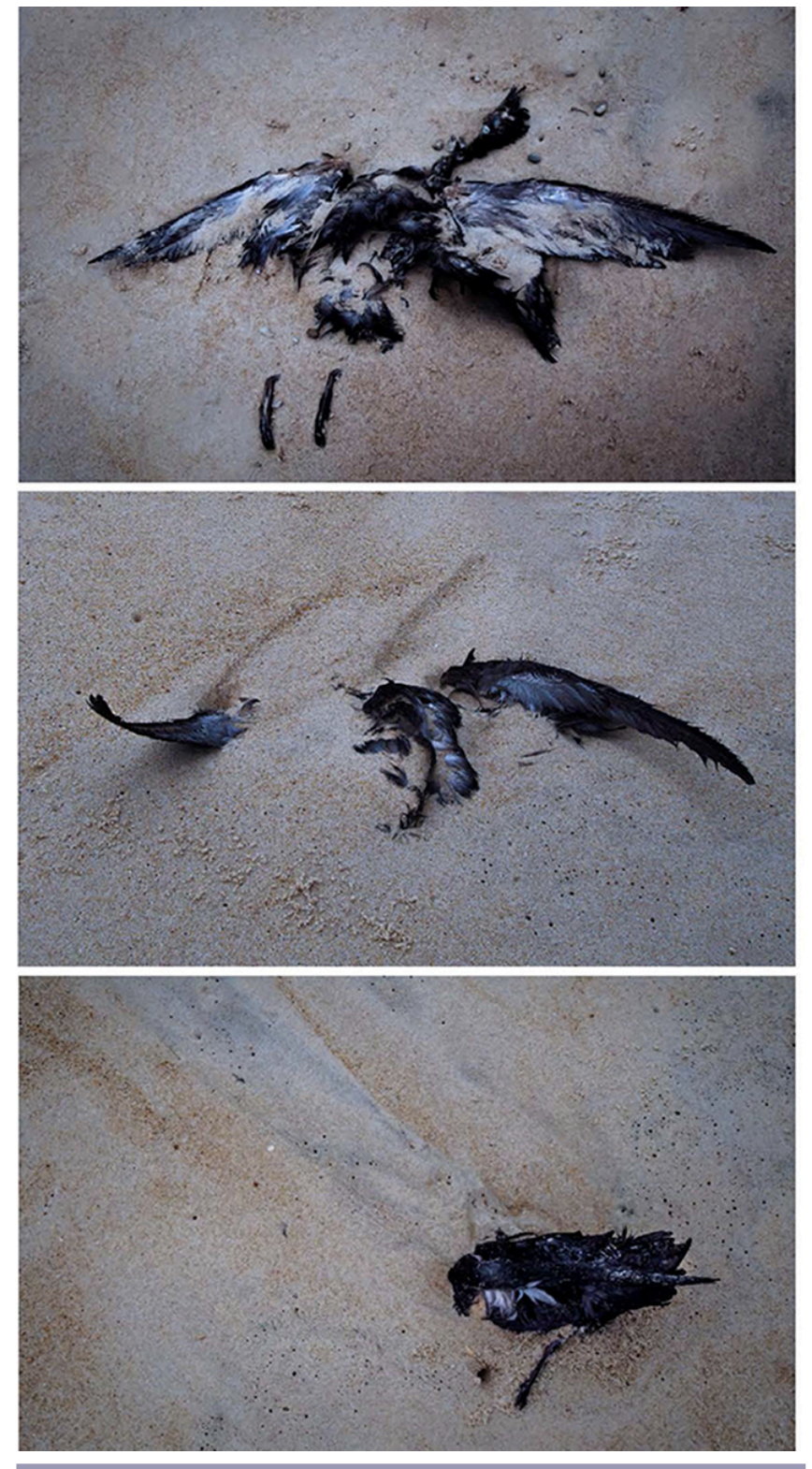

Fig. 3. Shearwater decay triptych, Southeast Queensland and Northern New South Wales, Australia. 2013 December 06-2014 January 28. Source: Author's own photographs.
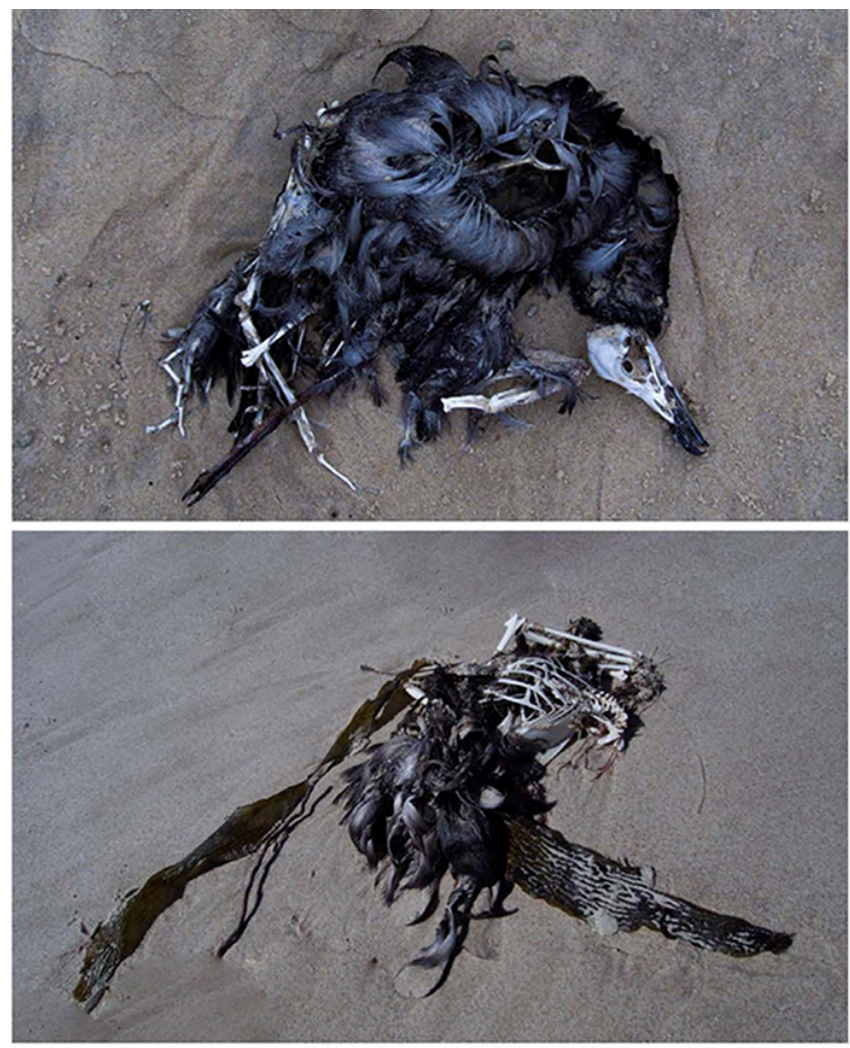

To provoke questions, the content of Figures 2 and 3 is similar to Figure 1. The production processes, however, enable larger, detailed compositions that more adequately and sensuously represent the delicate aesthetics, subtle colorings, and fragility of this species: the blue-black, glossy feather tips, the soft grey down, and the slender white bones. Applying a more minimal approach to montage, the photographs are arranged as a triptych to orientate viewers according to the temporal processes of burial (Fig. 2) and decay (Fig. 3) as the bodies (dis)integrate into the landscape. Importantly, the simple composition of bodies on washed sand leaves no clue as to the causal agents implicated in their deaths. The overall impact is one of beauty, vulnerability, 
and uncertainty in which the photographs show, rather than tell, a story. Viewers are compelled to ask many questions before a narrative, let alone any resolutions, are reached. As Ryan argues, the sublime prompts us to explore how we make sense of our experience and to ask: "Why and how does this object move me?" (Ryan 2001:265).

The tensions articulated by Peeples (2011) are instructive in answering Ryan's question and indicate that the combination of Figures 1, 2, and 3 has the potential to cultivate the inherent discord of the sublime as viewers are confronted with the following contrasts: the beauty of the birds and the ugliness of an unceremonious death; the potential insignificance of one death and the magnitude of many deaths; the familiar landscape and the unfamiliar deathscape (Maddrell and Sidaway 2010); the security of a photograph and the insecurity of actual events; and the certainty of death and the uncertainty of the causal processes.

As an example of the potential responses made possible through these images, the following questions are drawn from the following: (1) unsolicited questions asked by approximately ten residents and tourists using the beach during the capture of the images; (2) a web-based review of local, national, and international news reports (including media releases from state and local governments), NGO websites, and informal blogs concerning shearwater wrecks; and (3) reflections of the author in response to the images.

\section{Why?}

Are these birds of the weather? Were they exhausted through too little or too much wind? Or are they the starving victims of overfishing or rapid population growth? Did they set off malnourished or did they fail to find food on the way? Have they been exposed to some form of pollution or unknown contaminant? Perhaps it is all, some, or none of these reasons.

\section{Why not?}

Is this a natural event in terms of incidence, frequency, and magnitude? What counts as natural in human-altered landscapes, in a human-altered world? If it is natural, is it desirable? If it were our own species, would we be so quick to dismiss this as a natural cycle? Certainly, death is an essential part of natural cycles, but what are the ethics of premature, preventable death?

\section{Immediate responses?}

Do these dead and dying birds represent a health hazard? Should I stay away, as recommended by local authorities, or should I seek to assist them? Would assistance involve ensuring a safe passage back through the surf zone to calmer, deeper waters or relocating individuals to wildlife rescue agencies? People appear to be using the beach as per normal, sunbathing among the bodies and surfing with the feathers. Should I be appalled that so many deaths of one species appear to invoke so little response in my own species? Are my responses alarmist?

\section{Implications for self and society?}

What is my role in these deaths? Are my practices implicated in these deaths? Why don't we know more about this species? Should we cease fishing? Should we take a more active role in climatechange mitigation? Are there unseen contaminants in the landscape that have/will affect other species too? Should we care more deeply for others in the landscape, the mass deaths of humans in this place would not be considered natural or ignored.
The unsolicited dialogue, web review, and the author's own reflections, contained responses related to each of these four question categories, i.e., why, why not, immediate responses, and implications for self and society, indicating the potential for such phenomena, i.e., the wrecks, to inculcate a sense of uncertainty and a desire to understand, to question, and to imagine what circumstances might have caused these deaths across a range of sources. Importantly, these questions are essentially imaginations suggestive of reflexive explorations that go beyond initial responses toward dialogue and the questioning of self and relationships with(in) broader systems.

\section{Developing emotional connections with those impacted by social- ecological change}

The questions generated indicate a range of emotional responses including fear, sadness, anger, disgust, and surprise that may arise from the content of such imagery, consideration of past experiences, and direct exposure as a viewer contemplates another's situation. However, with the exception of surprise, such negative emotional states are not considered productive forms of disturbance, especially in isolation (O'Neill and Nicholson-Cole 2009). Nevertheless, Joffe (2008:89) suggests that such stimuli can be "engaging" and that the act of looking can help bring viewers "into a new relationship" with that viewed. Hence, the drama of multiple dead bodies and close-up imagery may prompt awareness and an initial look with other, more productive, feelings, such as care and empathy, emerging through closer inspection and introspection. But how can the researcher/photographer ensure that viewers don't turn away after a preliminary glance?

One answer might lie, again, in the exploitation of uncertainty in which viewers are compelled to search for more clues in the minimalist compositions and the ambiguous application of montage. For example, viewers may query how many different individual birds are represented? What dimensions of time and/ or space have been collapsed in the montages and would prove accurate reinsertions between the images?

Another answer might lie in the tensions of the toxic sublime and postproduction techniques in which images cultivate both pleasant and unpleasant responses. Additional creative postproduction techniques have been applied in Figures 2 and 3 to ensure simple and dramatic images. Clutter and noise have been removed, clarity has been softened, vibrance has been enhanced, and the tone of the images has been standardized across the photographs to achieve images that more expressively represent the beauty of the birds, without producing a beautiful image. "Aestheticising the landscape" has the potential to heighten perceptions of loss, but is not without risks (Doyle 2007:132). In particular, in invoking a toxic sublime, it was important that any notions of beauty were juxtaposed with the obvious finality, but unknown significance, of the birds' deaths.

The photographs also represent the birds and the landscape from a nonthreatening, high-angle point-of-view. Viewed from above, these images are less likely to invoke an immediately fearful response, although this may come, more fruitfully, later in response to contemplation of causes.

Finally, some of the photographs capture the faces and the eyes of the deceased birds and may capitalize on the hardwired tendency of people to recognize these features in another, as noted 
in various disciplines including visual studies (e.g., Mitchell 2002) and neuroscience (e.g., Batki et al. 2000, Emery 2000).

In combination, I argue that these content choices and compositional techniques reflect a relational scale, i.e., a scale that has the potential to foster close associations in the face of unanticipated phenomena without repelling, overwhelming, or desensitizing viewers.

\section{Providing a foundation for precautionary behavioral change in uncertain contexts}

I have demonstrated the creative potential of photography, through a range of deliberate compositional choices, to form part of an evocative visual agenda to enhance engagement with socialecological change discourses. In so doing, I also demonstrate the role of photography in human-altered landscapes to precede precautionary behavioral change through raising awareness of issues hitherto unseen, developing emotional responses and feelings that challenge pre-existing ways of relating, and by provoking complex, questioning, and imaginative narratives that seek to identify causes, responsibilities, and appropriate responses.

In particular, the narratives generated indicate the potential to develop notions of place as "a nexus of multiple and unfolding chains of events...[in which] multiple pasts and futures are enfolded into immediate reality" (Reid and Taylor 2003:87), supporting concepts of "ecological citizenship" in which "common concerns (and concerns grounded in the commons)" can lead to "expansive spatiotemporal horizons of responsible action" (Reid and Taylor 2000:440).

Indeed, although the causes of the wrecks are ambiguous, the immediate consequences for the individual birds are more obvious. The skull depicted in Figure 3 represents an iconic symbol of death and was selected to function as a reminder that although changed social-ecological contexts can be concerning for a number of reasons, a particular concern arises from the potential inability of species to cope with or adapt to change. Consequently, the meanings generated through these events and images can become an important element in developing empathetic connections with those (humans and nonhumans) impacted by social-ecological change toward precautionary behavioral change. As Morphy contends, "meaning pre-exists action and...is one of the things that makes agency possible..." (2009:14).

The implications for the role of imagery as "produced and producing" (Morphy 2009:15) in response to social-ecological change are indicated by Gablik who argues: "art that is grounded in the realization of our interconnectedness and intersubjectivity - the intertwining of self and others - has a quality of relatedness that cannot be fully realized through monologue: it can only come into its own in dialogue, as open conversation" (1992:4). In particular, the multiplicity and complexity of potential questions and emotional responses identified earlier serve as an important reminder that consideration of aesthetics needs to be sensitive to socio-cultural contexts. Indeed, "people who use works of art, interact with works of art, respond to works of art, do so with some background of knowledge and experience..." (Morphy 2009:14). Hence, the value of imagery in prompting reflexive agency is likely to be place-based and/or culturally specific indicating that an area for future research is to explore the degree to which an evocative visual approach results in precautionary behavioral change and the place-based or cultural specificity of associated agency.

\section{CONCLUSION}

The ability to identify social-ecological change, question possible causes, and imagine responses is essential to adaptation and transformation in changing circumstances. As Hansen (2010) noted, such issues are not self-emergent; they need to be constructed. This does not necessarily imply that change is undetectable or obscure, but that perhaps more attentive and empathetic ways of seeing need to be established. This is consistent with an element of Mitchell's (2002:170) counter-thesis on visual culture that suggests the need for "a meditation on blindness, the invisible, the unseen, the unseeable, and the overlooked." I have demonstrated that one way this can be achieved is through the use of novel imagery to invoke sustainability discourses that question phenomena in familiar, human-altered landscapes. As Peeples (2011:374) noted, it is not the most concerning environmental issues that inspire responses but those "most evocatively articulated."

The evocative visual agenda that I presented pays careful attention to interdisciplinary insights from several visual disciplines, especially geography, ecology, and environmental communication. These disciplines demonstrate the efficacy of photographic images containing local and iconic content and also those with more universal appeal, such as animals. It also experimented with various compositional techniques including montage, point-ofview, and creative postproduction adjustments. Ultimately, the visual agenda presented differs from most approaches to environmental and sustainability communication in that the production processes are concerned with invoking questions and imagination rather than making particular claims or constructing particular issues. To borrow from Mjaaland (2009), the images represent "evocative encounters."

My findings demonstrate that the construction of issues need not be a process controlled and completed by an individual actor, discipline, governing body, or other social organization. Instead, potential issues can be evocatively and ambiguously raised to prompt questioning and imaginative forms of engagement instead. Insights and responses can be developed through connective aesthetics (Gablik 1992) or the activation of associative capacity (Scheffer et al. 2015). This approach prompts us to ask questions of the landscape and to develop emotional connections with what we find. It encourages us to look, to establish new ways of relating, and to ask questions of ourselves as we seek to comprehend changing contexts. Rather than build on the increasing technological ability to depict what might be with ever more accuracy and realism, I have focused on contemporary social-ecological change and prompting sustainability discourses regarding what such changes might mean. These are not images of the future; they are images for the future.

Responses to this article can be read online at: http://www.ecologyandsociety.org/issues/responses. $\mathrm{php} / 7925$ 


\section{Acknowledgments:}

The author would like to thank Prof. T. F. Smith and two anonymous reviewers whose suggestions have greatly improved this paper.

\section{LITERATURE CITED}

Alpers, S. 1991. The museum as a way of seeing. Pages 25-32 in I. Karp and S. D. Lavine, editors. Exhibiting cultures: the poetics and politics of museum display. Smithsonian, Washington, D.C., USA.

Anderson, K., and S. J. Smith. 2001. Editorial: emotional geographies. Transactions of the Institute of British Geographers 26:7-10. http://dx.doi.org/10.1111/1475-5661.00002

Baldwin, C., and L. Chandler. 2010. "At the water's edge": community voices on climate change. Local Environment 15:637-649. http://dx.doi.org/10.1080/13549839.2010.498810

Batki, A., S. Baron-Cohen, S. Wheelwright, J. Connellan, and J. Ahluwalia. 2000. Is there an innate gaze module? Evidence from human neonates. Infant Behavior and Development 23:223-229. http://dx.doi.org/10.1016/S0163-6383(01)00037-6

Bissell, D. 2009. Visualising everyday geographies: practices of vision through travel-time. Transactions of the Institute of British Geographers 34:42-60. http://dx.doi.org/10.1111/j.1475-5661.2008.00326. $\underline{\mathrm{X}}$

Crang, M. 2010. The death of great ships: photography, politics, and waste in the global imaginary. Environment and planning $A$ 42:1084-1102. http://dx.doi.org/10.1068/a42414

Davidson, J., and C. Milligan. 2004. Embodying emotion sensing space: introducing emotional geographies. Social and Cultural Geography 5:523-532. http://dx.doi.org/10.1080/1464936042000317677

Diehl, C. 2006. The toxic sublime. Art in America 94(2):118-123.

Dockerty, T., A. Lovett, G. Sünnenberg, K. Appleton, and M. Parry. 2005. Visualising the potential impacts of climate change on rural landscapes. Computers, Environment and Urban Systems 29:297-320. http://dx.doi.org/10.1016/j.compenvurbsys.2004.05.004

Doel, M. A., and D. B. Clarke. 2007. Afterimages. Environment and Planning D: Society and Space 25:890-910. http://dx.doi. org/10.1068/d436t

Doyle, J. 2007. Picturing the clima(c)tic: Greenpeace and the representational politics of climate change communication. Science as Culture 16:129-150. http://dx.doi.org/10.1080/095054$\underline{30701368938}$

Emery, N. J. 2000. The eyes have it: the neuroethology, function and evolution of social gaze. Neuroscience and Biobehavioral Reviews 24:581-604. http://dx.doi.org/10.1016/S0149-7634(00) $\underline{00025-7}$

Gablik, S. 1992. Connective aesthetics. American Art 6(2):2-7. http://dx.doi.org/10.1086/424147

Godemann, J., and G. Michelsen. 2011. Sustainability communication - an introduction. Pages 3-11 in J. Godemann and G. Michelsen, editors. Sustainability communication: interdisciplinary perspective and theoretical foundations. Springer, Dordrecht, the Netherlands. http://dx.doi.org/10.1007/978-94-007-1697-1 1
Hansen, A. 2010. Environment, media and communication. Routledge, Oxford, UK.

Hansen, A., and D. Machin. 2013. Researching visual environmental communication. Environmental Communication 7:151-168. http://dx.doi.org/10.1080/17524032.2013.785441

Hitt, C. 1999. Toward an ecological sublime. New Literary History 30:603-623. http://dx.doi.org/10.1353/nlh.1999.0037

Howell, R. A. 2011. Lights, camera... action? Altered attitudes and behaviour in response to the climate change film 'The Age of Stupid'. Global Environmental Change 21:177-187. http://dx.doi. org/10.1016/j.gloenvcha.2010.09.004

Joffe, H. 2008. The power of visual material: persuasion, emotion and identification. Diogenes 55:84-93. http://dx.doi. org/10.1177/0392192107087919

Kollmuss, A., and J. Agyeman. 2002. Mind the gap: why do people act environmentally and what are the barriers to proenvironmental behavior? Environmental Education Research 8 (3):239-260. [online] URL: http://web.env.auckland.ac.nz/ courses/geog320/resources/pdf/LA21-EnvEd/Kollmuss_Agyeman_2002. pdf

Lorenzoni I., S. Nicholson-Cole, and L. Whitmarsh. 2007. Barriers perceived to engaging with climate change among the UK public and their policy implications. Global Environmental Change 17:445-459. http://dx.doi.org/10.1016/j.gloenvcha.2007.01.004

Maddrell, A., and J. D. Sidaway, editors. 2010. Deathscapes: spaces for death, dying, mourning and remembrance. Ashgate, Farnham, UK.

March, K., and R. Brewin. 2013. Dead sea birds wash up along the south coast. ABC Esperance. 2013 November 20. [online] URL: http://www.abc.net.au/local/stories/2013/11/20/3895163. $\underline{\text { htm }}$

Marx, S. M., E. U. Weber, B. S. Orlove, A. Leiserowitz, D. H. Krantz, C. Roncoli, and J. Phillips. 2007. Communication and mental processes: experiential and analytic processing of uncertain climate information. Global Environmental Change 17:47-58. http://dx.doi.org/10.1016/j.gloenvcha.2006.10.004

Mjaaland, T. 2009. Evocative encounters: an exploration of artistic practice as a visual research method. Visual Anthropology 22:393-411. http://dx.doi.org/10.1080/08949460801986145

Mistry, J., A. Berardi, L. Haynes, D. Davis, R. Xavier, and J. Andries. 2014. The role of social memory in natural resource management: insights from participatory video. Transactions of the Institute of British Geographers 39:115-127. http://dx.doi. org/10.1111/tran.12010

Mitchell, W. J. T. 2002. Showing seeing: a critique of visual culture. Journal of Visual Culture 1:165-181. http://dx.doi. org/10.1177/147041290200100202

Morphy, H. 2009. Art as a mode of action: some problems with Gell's art and agency. Journal of Material Culture 14(1):5-27. http://dx.doi.org/10.1177/1359183508100006

Moser, S. C. 2010. Communicating climate change: history, challenges, process and future directions. Wiley Interdisciplinary Reviews: Climate Change 1:31-53. http://dx.doi.org/10.1002/ $\underline{\text { wcc. } 11}$ 
Moser, S. C. 2014. Communicating adaptation to climate change: the art and science of public engagement when climate change comes home. Wiley Interdisciplinary Reviews: Climate Change 5:337-358. http://dx.doi.org/10.1002/wcc. 276

Nicholson-Cole, S. A. 2005. Representing climate change futures: a critique on the use of images for visual communication. Computers, Environment and Urban Systems 29:255-273. http:// dx.doi.org/10.1016/j.compenvurbsys.2004.05.002

O’Neill, S. J. 2013. Image matters: climate change imagery in US, UK and Australian newspapers. Geoforum 49:10-19. http://dx. doi.org/10.1016/j.geoforum.2013.04.030

O’Neill, S. J., and S. Nicholson-Cole. 2009. "Fear won't do it" promoting positive engagement with climate change through visual and iconic representations. Science Communication 30:355-379. http://dx.doi.org/10.1177/1075547008329201

O’Neill, S. J., and N. Smith. 2014. Climate change and visual imagery. Wiley Interdisciplinary Reviews: Climate Change 5:73-87. http://dx.doi.org/10.1002/wcc.249

Peeples, J. 2011. Toxic sublime: imaging contaminated landscapes. Environmental Communication 5:373-392. http://dx.doi. org/10.1080/17524032.2011.616516

Pink, S. 2003. Interdisciplinary agendas in visual research: resituating visual anthropology. Visual studies 18(2):179-192. http:// dx.doi.org/10.1080/14725860310001632029

Ravetz, J. R. 2006. Post-normal science and the complexity of transitions towards sustainability. Ecological Complexity 3:275-284. http://dx.doi.org/10.1016/j.ecocom.2007.02.001

Reid, H., and B. Taylor. 2000. Embodying ecological citizenship: rethinking the politics of grassroots globalization in the United States. Alternatives: Global, Local, Political 25:439-466.

Reid, H. G., and B. Taylor. 2003. John Dewey's aesthetic ecology of public intelligence and the grounding of civic environmentalism. Ethics and the Environment 8(1):74-92. http:// dx.doi.org/10.1353/een.2003.0011

Roberts, E. 2013. Geography and the visual image: a hauntological approach. Progress in Human Geography 37:386-402. http://dx.doi.org/10.1177/0309132512460902

Rose, G. 2000. Practising photography: an archive, a study, some photographs and a researcher. Journal of Historical Geography 26:555-571. http://dx.doi.org/10.1006/jhge.2000.0247

Rose, G. 2008. Using photographs as illustrations in human geography. Journal of Geography in Higher Education 32:151-160. http://dx.doi.org/10.1080/03098260601082230

Ryan, V. L. 2001. The physiological sublime: Burke's critique of reason. Journal of the History of Ideas 62:265-279. http://dx.doi. org/10.1353/jhi.2001.0018

Scheffer, M., J. Bascompte, T. K. Bjordam, S. R. Carpenter, L. B. Clarke, C. Folke, P. Marquet, N. Mazzeo, M. Meerhoff, O. Sala, and F. R. Westley. 2015. Dual thinking for scientists. Ecology and Society 20(2):3. http://dx.doi.org/10.5751/ES-07434-200203
Schneider, B. 2012. Climate model simulation visualization from a visual studies perspective. Wiley Interdisciplinary Reviews: Climate Change 3:185-193. http://dx.doi.org/10.1002/wcc.162

Schriever, J. 2013. Exhaustion killed hundreds of mutton birds found on Middleton Beach. Advertiser, 11 November. [online] URL: http://www.adelaidenow.com.au/news/south-australia/exhaustionki...ton-birds-found-on-middleton-beach/story-fni6uolm-1226756815987

Schwartz, J. M. 1996. The geography lesson: photographs and the construction of imaginative geographies. Journal of Historical Geography 22:16-45. http://dx.doi.org/10.1006/jhge.1996.0003

Seppänen, J., and E. Väliverronen. 2003. Visualizing biodiversity: the role of photographs in environmental discourse. Science as Culture 12:59-85. http://dx.doi.org/10.1080/0950543032000062263

Shaw A., S. Sheppard, S. Burch, D. Flanders, A. Wiek, J. Carmichael, J. Robinson, and S. Cohen. 2009. Making local futures tangible - synthesizing, downscaling, and visualizing climate change scenarios for participatory capacity building. Global Environmental Change 19:447-463. http://dx.doi. org/10.1016/j.gloenvcha.2009.04.002

Sheppard, S. R. J. 2001. Guidance for crystal ball gazers: developing a code of ethics for landscape visualization. Landscape and Urban Planning 54:183-199. http://dx.doi.org/10.1016/ $\underline{\text { S0169-2046(01)00135-9 }}$

Sheppard, S. R. J. 2005. Landscape visualisation and climate change: the potential for influencing perceptions and behaviour. Environmental Science and Policy 8:637-654. http://dx.doi. org/10.1016/j.envsci.2005.08.002

Smith, T. F. 2009. Beyond knowledge: a neo-research approach to climate change adaptation. Pages 30-44 in J. Martin, M. Rogers, and C. Winter, editors. Climate change responses across regional Australia: social learning and adaptation. Victorian Universities Regional Research Network Press, Ballarat, Australia.

Thomsen, D. C., T. F. Smith, and N. Keys. 2012. Adaptation or manipulation? Unpacking climate change response strategies. Ecology and Society 17(3):20. http://dx.doi.org/10.5751/ ES-04953-170320

Wolff, J. 2012. After cultural theory: the power of images, the lure of immediacy. Journal of Visual Culture 11:3-19. http://dx.doi. org/10.1177/1470412911430461 